which have been submitted to a crucial time-test. The matter stands thus : whatever operation we may select for the relief of a stricture, we shall fail to cure the patient; for, if he be really cured, he requires no after-treatment-prolonged for his life, be it observed. But, if no such treatment be pursued, we shall find out that the patient will infallibly have a return of his old complaint; thus proving that an operation, unless supported by a well regulated course of after-treatment for life, is only followed by temporary results. As a rule, there is no difficulty in restoring a contracted urethra to its normal calibre; but it is impossible to preserve the good we have achieved, unless we pass an instrument from time to time. We cannot cure; we can only remove troublesome effects, which will infallibly return unless we persist in our treatment. Pathologically speaking, no stricture is curable; but, practically, nearly all strictures are remediable. At whatever time after an operation we examine the urethra with a bougie a boule, we shall find that the pathological state is not removed, but only modified in some slight degree; for the soft velvety condition of the mucous membrane is replaced in the strictured part by a gritty unevenness of tissue, as felt by the bougie a boule.

A short time ago, I had an opportunity of examining, post mortem, the strictured urethra of a patient whose canal I had a year previously dilated up to a large size. Before I removed the parts, I passed a fullsized bougie into the bladder with ease, thus showing that the canal was still of a normal calibre; but, on laying open the bulb, the remains of a tunnel-stricture were very visible in the form of three longitudinal ridges of induration, each about one and a half inches long, and about the one-sixteenth of an inch in depth. These ridges did not disappear when the urethra was stretched laterally, and their yellowish appearance contrasted strongly with the healthy portions of the mucous membrane. Mr. Timothy Holmes records a case of death after the strictures had been forcibly ruptured, in which "the traces of the two strictures were quite perceptible in the urethra", although both admitted an ordinary-sized instrument. (See Trans. Path. Society, vol. xxi, p. 280.)

I have in my experience seen a few cases which would seem to prove that now and then the indurated lymph is wholly absorbed, and that the strictures were really and truly cured. But any deductions drawn from a few isolated cases must be regarded as worthless for practical purposes, as the following case will show, proving how unsafe it is to predict that there will be no relapse even under the most favourable conditions. A patient, whose strictured urethra I had restored by gradual dilatation to about its normal calibre, remained for two years without having any instrument passed, at the end of which time he came to report himself. The urethra was still as capacious as when I had last seen him, and the largest sized instrument could be passed with ease. Apparently, nothing could be more satisfactory; but, six months later, the patient presented himself, and said that contraction was beginning to return. I tried to pass the same sized bougie as I had done on a former occasion; but I could not, and had to use one two sizes smaller. One of the reasons why this patient had gone so long without any relapse was, that his urethra was naturally very capacious; and another was, that I had dilated his stricture up to an excessively large size, thus putting off the relapse for an unusually long period.

Of all the cases of operation for stricture that have come under my care, in which the operation was performed by myself or others, I have never yet met with one in which an examination with the bougie a boule did not detect some remains of the strictures, though years might have passed away after the operation. Nearly all the published cases of operation for stricture have been deprived of most of their value from the fact that the authors have given only the temporary effects of the operation, and not the trustworthy results which are to be seen a couple of years afterwards. On this subject, Mr. Cooper Forster made a most pithy and apposite remark in reference to a case of operation for stricture which was narrated at the Clinical Society. He said, "I do not care to see the patient now, but I should very much like to examine him two years hence." Herein lies the whole gist of the subject. The present state of the question is this : no surgeon has as yet been able to produce that evidence which would alone carry conviction; and so long as this is wanting, and we every day have cases of relapse after each and every kind of operation, we must come to the conclusion that no operation is desirable except in certain exceptional circumstances. Hence, therefore, as no operation can cure a patient, it is our duty never to recommend such a procedure unless it is absolutely called for, as we are not justified in endangering the safety of a patient's life, just to humour his whim, when we can achieve, by gradual dilatation, which is absolutely free from all danger, all that is open to us. The treatment of a stricture is a treatment for lifetime, and he who fails to recognise this important truth deceives him. self or his patient. Fifty years have now rolled away since the great Delpech wrote the following words, and no English surgeon has been able to reverse his judgment. "Quant à la coarctation elle-même, il est presque superflu de dire que nous avons bien vérifié combien cette affection est incurable, et ne peut être que soulagée passagèrement, et conserve une tendance invincible à se reproduire insensiblement. Il en est constamment ainsi, quels que soient les moyens par lesquels elle a été combattue. Ce serait abuser de la crédulité des malades et des médecins, et se jouer de la vérité, que de prétendre le contraire." (Chirurgit Clinique, vol. i, p. 273.)

\section{ETHER AND CHLOROFORM.}

\section{By W. C. B. FIFIELD, M.D.Harvard, M.R.C.S.Eng., of Boston.}

Some one has been good enough to send me six copies of the BRITISH MEDICAL JourNal, of the date May 8th, I875, containing a letter from Dr. Thomas Skinner of Liverpool, entitled Ether and Chloroform.

I had some idea of answering this letter, when I perceived that Dr. Skinner had answered it himself by saying that, out of hundreds whom he had witnessed administering chloroform in Edinburgh, London, Liverpool, and elsewhere, there are not six from whom he would take it. Could any statement be so severe as this? Could anything be more startling? Could any words give a more vivid idea of what a dangerous deadly agent is chloroform, or waken more quickly a vigorous public attempt on the part of the British public to forbid its use as an anæsthetic, when out of the hundreds or thousands of British surgeons who are daily employing it there are not six from whom Dr. Skinner would take it ?

Surely, British wisdom was justified of her children when Dr. Sinclair told him (Dr. Skinner) that an American jury would deal very hard with him if a death occurred from his administration of chloroform, when even Dr. Skinner admits that he would not take chloroform from six of all the hundreds he has witnessed giving it.

An American jury would probably consider the matter in this light, viz., that whosoever administered chloroform by inhalation for relief from pain, knowing that sudden death may result from causes too numerous to mention, and even when no cause can be found for such death other than the agent employed, knowing also that another agent equally capable of producing such anæsthesia exists, which has been shown to be far more safe than chloroform, viz., sulphuric ether, shall be held criminally responsible for his temerity.

Leaving Dr. Skinner, I would ask to call attention to the various discussions and reports here in Paris on the subject of chloroform.

Firstly, Dr. Albert Bergeron has written a book, and a very good book it is, entitled Chloroform in the Surgery of Children. In this book, he seeks to prove exactly what Dr. Skinner has denied; and I heard Dr. St. Germain lecture about Dr. Bergeron's book at the Hôpital des Enfants Malades, and agree with Dr. Bergeron in toto, viz., that if chloroform can ever be given safely, it is to very young children. M. Bergeron is frankness itself. Speaking of cases where death occurs hours, or even days, after the administration of chloroform, he says : "But it is no longer the same in the series of facts, unhappily too numerous, where one sees death come abruptly, suddenly, the patient still on the operating-table, the surgeon having just finished, or even not having commenced his operation. These cases are not doubtful ; it is truly to chloroform that they ought to be attributed. The discussion of them is difficult; and these are they which constitute the true necrology of chloroform, which the surgeons of Boston and Lyons have so often brought forward. Far be it from me to acquit chloroform with an adult."

M. Bergeron, however, meets with some ugly facts in regard to the perfect safety of chloroform in young children; notably, the five observations reported by $M$. Bouvier; but he escapes ingeniously from three or four of them. Hæmorrhages, relatively considerable, had taken place with three children; and the fourth has been recalled to life by artificial respiration, faradisation of the diaphragm, and methodical compression of the abdomen. This case was that of a child four years old. The fifth observation has been recorded at Berlin ; it is that of a child, aged four years and three months. It was for a simple catheterism. Two or three minutes passed between the last inhalations of chloroform and the moment when the catheter was introduced; and during this interval the child breathed only pure air; the respiration and the pulse were carefully watched. It was at the moment that the catheter penetrated the bladder that respiration stopped; and, in spite of all efforts, the child died. It is said that the sleep had come 
on quickly, and that the quantity of chloroform was less than usually employed for children of this age. There was no necropsy. M. Bergeron says that he receives this case with difficulty, as a post mortem examination might have otherwise explained the death. M. Bergeron admits that, at a certain point chloroform may be considered as a toxic agent, and that in large doses it brings death.

In the lecture of M. St. Germain, to which I referred, he related some moving anecdotes of death from chloroform. One of these was that of a man who entered a hospital for the reduction of a dislocated hip. He had chloroform ; the dislocation was quickly reduced; but the man was dead. M. St. Germain attributed many of these deaths during chloroformisation to the impurity of the agent employed, and the carelessness of assistants who will watch the surgeon. He referred to a point to which much attention is now given, that at the commencement of chloroformisation the pupil of the eye first becomes dilated ; then, when perfect anæsthesia takes place, contracted; if waking or vomiting occur, the phenomena are reversed. During operations, the pupil must be maintained at the exact point of contraction, and it is a signal that the operation may be commenced. Hence, at present, in all Parisian hospitals, one sees the internes carefully watching the iris; but, in spite of all this, I saw the other day at La Charité, in the service of M. Gosselin, a patient suddenly lowered to the floor, head first (Nélaton's method), and vigorously flapped with towels to restore consciousness.

Dr. Skinner says " in all operations on the head and abdomen (teeth and jaws excepted) ether is best"-why, if chloroform be better than ether, I cannot see. Yet, here in Paris, chloroform is forbidden in disarticulation or resection of the jaws. I heard the other day a free professor at the École Pratique instructing his pupils in these operations. "One can't use chloroform", said he, "and you must make haste." M. Verneuil operates "avec une rapidité effroyante".

But the strangest proposition to bring about anæsthesia with the smallest possible amount of chloroform is that of M. Forné, who presented a paper to the Society of Surgery, entitled "Contribution to Surgical Anæsthesia", and upon which M. Lannelongue has written a report. It is a new method of "anæsthesia en deux temps". It consists in this. First, the patient is made to take a single dose of chloral varying between thirty and sixty grains, according to age (mark the minimum). The surgeon then waits until sleep may be obtained, usually less than an hour. At this moment, one proceeds to theadministration chloroform. M. Lannelongue says that this proceeding rests on the basis of the ass ociation of a narcotic with an anæsthetic, of which the first idea came to Claude Bernard, who experimentally applied it at the College of France. In surgery, Nussbaum, Rigault, and Sarrazin, Guibaut de St. Brieuc, Lutté, Goujon, and Sumay have applied it with success. M. Lannelongue sums up the gist of M. Forne's contribution as follows "Inhalations of chloroform cease to be dangerous when administered during a chloralic sleep, by means of an apparatus admitting air freely to pass." M. Forné has, says M. Lannelongue, clearly stated the question, Is it possible to suppress the dangers inherent to inhalations of anæsthetiques? This is evidently the culminating point of the problem of anæsthetiques. The dangers of the employment of anæsthetiques vary according to the state of wakefulness or somnolence of the subject. During wakefulness, it is necessary to surmount resistance, emotion, fear, often very great. Thence arise two sorts of inconveniences conducting to veritable dangers. On the one side, to pass the period of excitability, it is necessary to give a quantity of chloroform as much greater as this period is longer. The patients are thus exposed to a true poisoning. On the other side, fear and fright with pusillanimous subjects, and they are very numerous, suffice for rendering an account of these cases when death has been rapid after the absorption of a small quantity of chloroform. By placing patients in a preparatory sleep, their resistance is annihilated, their fear is avoided, the economy is surprised by causing it to pass from sleep, which one can consider as the first degree of anxsthesia, to a complete insensibility.

The discussion which followed this report is most interesting.

M. Dolbeau said that for some time he had been struck with the danger of giving chloroform to patients who had taken chloral. $\mathrm{He}$ had remarked a tendency to chill and coldness, which was progressive. $\mathrm{He}$ cited cases. The first was that of a lady, with fissure of the anus, who habitually took syrup of chloral. When he arrived to make the operation, she was asleep ; he could only half awaken her. Still, he chloroformed her in this state. He must admit that he used only a very small amount of chloroform, still he had very great difficulty to awaken her, and he affirmed that her state was sufficiently alarming. She spoke a few words, then slept again ; and, although the weather was very hot, she continued to grow cold. Although in haste to go, he was obliged to remain with her more than an hour. The result was at last fortunate. Last year, he had seen an English general returned from India, in whom he had occasion to resect the lower jaw. He chloroformed the patient easily, and the awakening was prompt; but he remarked a singular tendency to grow cold, and to sleep again. He remained two hours with him ; and when he was obliged to leave, his fears were far from being quieted. He left him in the hands of his aid, a doctor of medicine, much accustomed to the management of chloroform. Two hours later, he again saw the patient; he was then in a state of probable death; and it was only the next day that he was better. $\mathrm{He}$ then learned that the patient had taken ro grammes (150 grains) of chloral before the operation. Hence M. Dolbeau has been brought to the conviction that it is dangerous to chloroform a patient who has taken chloral. It is necessary beforehand to inquire if one has taken chloral. After the taking of chloral, a very small amount of chloroform is required, and it is a phenomenon with which he had already occupied himself, viz., the medico-legal question, if it was possible to make an anæsthetic sleep succeed to a natural sleep. I make here a little digression to state that this is possible under certain precautions, and in this case with very little chloroform. Most often with adults, when one brings close to the face of an adult plunged in a natural sleep a compress wet with chloroform, an abrupt waking, mingled with agitation and convulsions, is provoked ; but with children it is possible to make them pass from the natural to the anæsthetic sleep.

M. Demarquay declared that chloroform alone was sufficiently to be dreaded without chloral. He had witnessed this tendency to grow cold brought about by chloroform itself. Only some days since, he had chloroformed a lady for the removal of a tumour of the breast. There was a complete syncope ; and, in spite of frictions, artificial respiration, etc., he had great difficulty to recall her to life. He revolted from this union of chloral and chloroform.

M. Sée rose against two affirmations of M. Forné. The first is, that the danger of chloroform is in ratio to the dose employed. This is not sustainable. Witness the sudden deaths during the first inspirations. The second is, that the patients who rebel against chloroform run greater dangers than those who readily submit and are resigned. Witness children, who make the greatest resistance, yet are the most easily chloroformed by reason of the enormous inspirations which they make.

M. Perrin had given 3 grammes of chloral before administering chloroform, with good result.

M. Lannelongue thanked M. Dolbeau for having drawn attention to the danger of associating chloral and chloroform. The action of chloral is different, according to the subject. Above all, relatively to the rapidity of its action, chloral can at once be reproached with a constant tendency to slowing the beatings of the heart and coagulating the blood. He would recall to recollection that chloroform has often a very prolonged action upon patients, who in these cases do not rise above it, but extinguish themselves, so to speak. It is evident, in this case, chloroform has the deleterious effects of a poison slowly absorbed. Ought one in the same order of ideas to siderate absolutely patients even for the smallest operations? or, is it necessary to one-quarter or one-half chloroform them, as $\mathrm{M}$. Trélat had proposed? There was scarcely need, he thought, to insist on this latter practice; all surgeons follow it, so to speak, from instinct.

I recall that, when in Paris in I870, I saw patients on hospital operating tables, one-half or one quarter anæsthetised, undoubtedly from the instinctive conviction of the deadly nature of chloroform. The amphitheatres occasionally resounded with their yells.

M. Bergeron gives the following list, taken from the Traite' d'Anesthésie of Lallemand and Perrin, of the causes of sudden deaths, after or during the use of chloroform : I, pre-existing organic affections; 2, nervous state, emotion; 3, abuse of alcoholic drinks ; 4, intervention of surgery ; to which I would add, as seems to be admitted, 5, a peculiar influence of chloroform on the nervous organs, impossible to be foreseen, or to be remedied; 6 , the use of chloral. Thus, it would seem that it is not possible to give chloroform to any one safely, because it can never be known who there is who is not the subject of one or the other of these causes.

Do not all this paraphernalia of air-bags and special apparatus, these proposals to give chloral and opium before inhalation, in order to lessen the amount of chloroform employed, this timid, one-fourth and one-half anæsthesia, bespeak the inward conviction, the instinctive knowledge, that death from its use may come, and come quickly and immediately, and none can tell why or whence it came? Let us, then, see no more tears, or hear no more cases of fathers and mothers, of widows and orphans, who weep their dead; the dead who, but a moment ago, lay down trustingly for the reduction of a dislocation, the opening of a whitlow, or the removal of a wen. Let us employ ether, to which no reproach exists, except its evil smell. Unpleasant it may be, but its unpleasant smell is not to be compared to the umpleasant sight of a corpse; a corpse that, but for the employment of chloro- 
form, might still have been a living man or woman, or child. It has been objected that ether costs more. The expense of one funeral would pay for a deal of ether.

One word about the method of giving ether. Whilst it should be used freely at first, it is not necessary to abuse it. At a meeting of the Société de Chirurgie, a gentleman raised himself (a wonderful gymnastic feat) against the words, "American method" of giving ether. It was nothing but the method of Bonnet of Lyons, who turned on ether in floods, "et foudroyait ses malades". Bonnet had had two deaths. American surgeons call this drowning the patients, and I have often seen young internes sharply rebuked for so doing. One gentleman at the meeting referred to said that, in American hospitals, ether is given by special persons. This is not correct : internes, dressers, or even ward-tenders, often give it.

Lastly, as to what I said about ether in childbed, and proscription of the products of British brains. As to the use of ether in difficult cases of midwifery, I but spoke my own personal convictions; perhaps my countrymen will blame me for what I said in this regard. For England and British brains I cherish a most profound respect. The excellence of those brains is only surpassed by the goodness of English hearts.

Paris, May 1875 .

\section{FIBRO-NUCLEATED TUMOUR FROM THE DURA MATER OF THE CERVICAL PORTION OF THE SPINAL CORD.*}

By THOMAS S. DOWSE, M.D.,

Medical Superintendent of the Central London Sick Asylum, Highgate.

I HAVE ventured to trespass upon the time of this Society in bringing before its notice a form of tumour which, from its manner of growth, is of rare occurrence, and which will, I trust, be of interest not only in a medical, but also in a surgical point of view. To the physician, it will be interesting chiefly because of the symptoms of paralysis, which resulted from pressure upon the cord; and to the surgeon, because of its free mobility and non-adhesion to surrounding structures: a condition which might have led a bolder man than myself to attempt its extirpation. Nerve-tumours, we know, may originate in three different ways: $I$, from the free surfaces of the meninges; 2 , from the perivascular sheath; and 3 , from the neuroglia. Those which grow from the dura mater are usually of three kinds; viz., spindle-celled sarcoma, myxoma, and psammoma. I will now briefly introduce to you the chief clinical points in this case.

John Page, aged 34, was admitted into the Central London Sick Asylum at Highgate, August 21 ist, I872, and died July Ioth, 1874. His father died of phthisis at the age of forty-nine; but, with this exception, the family appeared to be healthy. There was no history of fits, insanity, paralysis, or syphilis; and, until he was thirty years of age, he himself for the most part enjoyed good health. About three years ago, he first noticed an enlargement in the right side of the neck, which gave him no pain, and which was usually considered by the medical men whom he consulted to be an enlarged gland. When he first came under my care, the swelling was about the size of a duck's egg, hard to the touch, and freely movable, lying in the posterior superior triangle. He said that for six years he had felt a weakness in the back, between the shoulders, so considerable that he had bought a band to support himself; and about four years ago he first experienced coldness and numbness at the tips of the fingers. This was at first 'ransitory, but at length became permanent, so that he was unable to pick up a pin or button his coat. This condition could not have arisen from want of muscular digital power, for he could bring the tips of the fingers well together, and was cognisant that they were so in apposition; but, when some foreign body was interposed between the cutaneous surfaces, this impressional cutaneous sense was not conveyed to his brain; hence he could not appreciate it. It was only through the medium of visual sense that he was made acquainted with its presence. If he took up a cup, he grasped it firmly, and held it tightly enough, while he was looking at it; but, immediately he lost sight of it, the grasp became relaxed, and down went the cup. This power of digital co-ordination was in abeyance from the want of cutaneous sense; but he was always helped by the aid of reflected as well as of direct vision: by the use of a looking-glass, for example. In addition to this condition of the hands, there was numbness of the right foot, which he dragged after him in walking. He complained of slight pain between

- Read before the Medical Section at the Annual Meeting of the British Medical Association in Norwich, August 1874 . the shoulders about the fifth dorsal vertebra, not increased by pressure, but augmented by fatigue. From this period, he gradually lost motor power in both upper and lower limbs; so that when admitted, two years ago, into the Hospital for the Paralysed, he was unable to walk, and could not even lift his feet from the ground.

When admitted into the Central London Sick Asylum in August 1872, he had a bad bed-sore, and was greatly prostrate. There was no want of cutaneous sensibility anywhere over the body, except at the tips of the fingers, more marked at the finger and thumb. In describing the symptoms, we will first commence at the

Sensorium. - Upon arriving, he felt stupid and heavy. He did not stagger. The eyes were bright, and there was an intelligent and even intellectual expression of countenance. The memory was good, and his mental powers were in no way affected. All his special senses were perfect. He had no shaking of the head or defect of speech; no divergence of the lingual movements; no dysphagia or dysphonia. Only when standing up or trying to walk was there spastic contraction of the left sterno-mastoid and trapezius muscles, drawing the head over the left shoulder. At ordinary times, inspiration was performed quietly enough; but, when he was not so well as usual, the breathing became jerky; he was unable to expand the chest; the head and shoulders were raised, and the extra-inspiratory muscles were brought into play. There was, in fact, defective temporary tone in the intercostal muscles, with some amount of cyanosis, and distressed facial aspect; and it was also quite evident, from his manner of breathing, that the diaphragm was more or less implicated. He said that his spine felt weak; but there was no deformity, and no especial tenderness upon pressure over the spinous processes.

Upper Extremities. - Both had undergone, and were undergoing, muscular wasting. The sense of touch was variable. When he closed the eyes, he sometimes appreciated the drawing of a penholder across his hand and fingers, even to its precise location. At other times, he did not feel it; or, if he did, he was not able to localise it. The movements of the upper extremities were very limited, on account of the muscular degeneration, which was more marked on the extensor than on the flexor side. The left hand was flexed; the fingers not into the palm, but the two distal phalanges upon the proximal. He had no voluntary power to extend the finger; but, when the left leg was automatically flexed, the fingers of the left hand became involuntarily extended. This relaxation of contractility in the fingers was immediately succeeded by contraction, again and again repeated. This coexistence of automatic nerve-force in the upper and lower extremities was a strange physiological phenomenon.

Sphincters and Bowels. - The bowels were usually very constipated, but occasionally relaxed. When this was the case, he had little or no power over the anal sphincter. He occasionally had retention of urine; and he always knew when this would be-not from general malaise, but from the offensive character of the urine.

Lozver Extremities. - The muscular and general wasting was not so much marked here as in the upper. The right and left legs were both alike affected, and he had not the least power to stand. There was no anæsthesia. When lying in bed, he was able to draw his legs toward him, flex, and then extend them. He could also cross one leg over the other. Occasionally, they were subject to reflex movements; but reflex conditions were certainly not a marked feature in this case.

From November 1873 , the man's condition changed but little. He at times suffered from retention of urine and very urgent dyspnœa. On July 9th, 1874 , the day preceding his death, the dyspncea was unusually urgent, and he became considerably cyanosed. On the night of the roth, he suddenly expired.

Necropsy, twelve hours after death. - Cadaveric rigidity was marked. The body was fairly nourished, and there did not appear to be any extreme muscular wasting of the lower extremities; but there was some atrophy of the intercostals. Upon removing the calvarium, the dura mater was found to be healthy. There was slight opacity of the arachnoid, with some effusion. The vessels of the pia mater were engorged with b'ack blood. When removed, the brain to all external appearance was healthy enough, as were the arteries, grey matter, and motor tract at the base. There was some chronic thickening of membranes lining the lateral ventricles, with supervascularity and slight excess of fluid. The removal of the cord was effected without hindrance as far as the second cervical vertebra. Here, occupying part of the cervical canal, was a foreign body, which was found to be in connection with the tumour of the neck to be presently described. When the cord and brain were removed, the seat of disease became readily apparent. In connection with the dura mater, posteriorly and laterally to the right, was found an abnormal substance pressing forwards and inwards upon the cord; and in one part especially it pushed the membranes before it to the size of a small bean, pressing forward the posterior nerves 